\title{
Sorghum-rice intercropping, a security system for the poorly drained soils of Southern Sudan
}

\section{T. E. Struif Bontkes}

Euroconsult, P.O. Box 441, 6800 AK Arnhem, Netherlands; and Department of General and Regional Agriculture, Agricultural University, P.O. Box 9101, 6700 HB Wageningen, Netherlands

Received 23 October 1985; accepted 16 January 1986

Key words: intercropping, sorghum, rice, poorly drained soils, stabilization of food production.

\begin{abstract}
In parts of Southern Sudan, sorghum production varies greatly from year to year due to the occurrence of floods in some years. These floods are caused by a combination of high rainfall within a short period, poorly drained soils, and varying micro-relief.

To improve the reliability of food production, a sorghum-rice intercropping system was tested in 1980 and 1981 on an area prone to such flooding. In these experiments sorghum proved to produce good yields at the expense of rice on areas which had been little flooded, whereas on waterlogged areas sorghum produced little while rice gave good yields. It may therefore be concluded that intercropping of rice with sorghum offers a good possibility to offset the loss of sorghum in wet years.
\end{abstract}

\section{Introduction}

A large part of Southern Sudan lies in the flood plain of the Nile. Its overall topography can be characterized as flat, with small differences in elevation. Most of the soils are alfisols or vertisols with poor internal drainage and little capacity to store available moisture, rendering them prone to both flooding and drought (Ilaco, 1982). The alfisols, which have a relatively sandy top-soil, are mostly found on the higher parts and the vertisols on the lower. It is possible that the alfisols were formed through lateral washout of the fine particles towards the lower parts, increasing the fertility and water-holding capacity of the latter.

The inhabitants of the region are semi-nomadic subsistence farmers who grow some maize, cowpea, tobacco, okra and pumpkin on areas close to their huts, where flooding is rare. Their main crop, however, is sorghum, which is grown on the high and intermediate areas around these fields. The farmers try to obtain two sorghum crops per year by ratooning the first crop or sowing a second crop at the 
end of the rainy season. Although differences in elevation within the fields are relatively small, the intermediate areas may be flooded from time to time during the rainy season. Fortunately, sorghum is relatively insusceptible to flooding (Doggett, 1970), but prolonged periods of waterlogging can nevertheless seriously reduce yields or may even kill the crop. Sorghum yields will therefore be relatively high in dry years and low in wet years. This makes food production in the flood plain unreliable: in dry years sorghum production may be sufficient to sustain a family, but in wet years cattle have to be sold to buy sorghum on the market if it is available at all.

In an attempt to obtain more reliable yields, the low areas were planted to rice. Yields were satisfactory (Ilaco, 1980), but because the low-lying areas constitute only a small portion of the farmers' fields it was obvious that this was not a solution to the problem. This experience, however, prompted the suggestion that rice might also succeed on the intermediate areas in years of high rainfall, so that a sorghumrice intercropping system would secure reliable food production: in dry years sorghum would grow well and in wet years rice would give good yields. To test these ideas a sorghum-rice intercropping experiment was set up on a field similar to those of the farmers.

The author published an earlier article on this subject outlining the general principles of this system (Struif Bontkes, 1985). The present paper elaborates on the technical background of the experiments.

\section{Materials and methods}

The experiments took place in 1980 and 1981 in a field at Anyidi, a village $25 \mathrm{~km}$ east of Bor. In order to compare the effects of different soil moisture conditions, a field was selected which was not entirely level: the differences were up to $20 \mathrm{~cm}$. Moreover the elevation of the field did not show a regular pattern, so that not only the absolute elevation was important for the extent of flooding but the relative elevation as well.

Since the purpose of the experiments was to develop improvements which would be applicable by the local farmers, no action was undertaken to alter the irregularities of the surface.

The soil was of the alfisol type, but the top-soil of the higher parts contained more sand than the lower parts. Sorghum was dibbled at $15 \mathrm{~cm}$ in the rows, which were 75 $\mathrm{cm}$ apart. Between each row of sorghum, two rows of rice were line-sown at a distance of $25 \mathrm{~cm}$. To assess the influence of different types of rice, the sorghum was combined with three rice cultivars with different characteristics: a quick-maturing short-straw cultivar (IR 24 in 1980 and IR 26 in 1981), a later-maturing short-straw cultivar (IR 269-26-3-3-3), and a photosensitive tall cultivar (Tau Ainho). In 1980 Serena, an exotic short-statured sorghum was used, but as the local population did not like its bitter taste and as the crop proved to be more susceptible to insect damage than the local cultivars, Lokarengan, an indigenous cultivar, was chosen in 1981. In line with local practice, no fertilizers or biocides were applied, and all labour was by hand. The most important data on the experiments are given in Table 1 . 
Table 1. Summary of the materials and methods of the sorghum-rice intercropping experiments in 1980 and 1981 .

\begin{tabular}{lll}
\hline & 1980 & 1981 \\
Sorghum cv. & Serena & Lokarengan \\
Rice cv. & IR 24 & IR 26 \\
& IR 269-26-3-3-3 & IR 269-26-3-3-3 \\
& Tau Ainho & Tau Ainho \\
Plot size & $5.0 \mathrm{~m} \times 3.75 \mathrm{~m}$ & $5.0 \mathrm{~m} \times 3.75 \mathrm{~m}$ \\
Replications & 6 & 6 \\
Date of sowing & 17 May & 6 May \\
Date of harvesting & & \\
Sorghum & 16 September & 9 September \\
IR 24/IR 26 & 4 October & 27 September \\
IR 269-26-3-3-3 & 16 October & 10 October \\
Tau Ainho & 24 October & 17 October \\
\hline
\end{tabular}

In order to establish whether variations in yield were due to differences in the hydrological condition of the plots, observations regarding the soil moisture conditions were made three times during the growing period. On the basis of these observations the plots were classified into three categories:

- dry, with on average $0-25 \%$ of the plot flooded;

- medium, with on average $25-75 \%$ of the plot flooded;

- wet, with on average 75-100 \% of the plot flooded.

As soil moisture conditions are partly a result of rainfall, the monthly rainfall was also recorded. For the statistical analysis of the results, two factors were taken into consideration: the rice cultivar and the replication, the latter representing the variation in field conditions. It was assumed that this variation would mainly be caused by the differences in soil moisture in different plots. The hypothesis, then, was that the rice and sorghum yields of the individual plots would vary significantly between the replications, but that the combined plot yields of both crops would not. This would mean that intercropping of sorghum and rice promotes stable production, little affected by varying moisture conditions. However, although the soil moisture characteristics of the plots turned out to be similar within some replications, there appeared to be differences within others. This renders it more difficult to prove that the hypothesis is correct but would not invalidate such an outcome.

\section{Results and discussion}

In both years there was prolonged flooding of the lower parts of the experimental area, while the highest parts were little flooded. Although the rainfall in 1980 and 1981 remained below average, the rainfall during the period May-September in these two years slightly exceeded that of the average rainfall in these months (Table 2). However, monthly rainfall figures may not give sufficient information regarding the soil moisture condition because this condition depends not only on the total monthly rainfall but also on the distribution of the rainfall over that month. 


\section{T. E. STRUIF BONTKES}

Table 2. Average monthly rainfall at Bor (1931-1970) and actual monthly rainfall at Anyidi, 1980 and 1981.

\begin{tabular}{lccc}
\hline & Bor & Anyidi & Anyidi \\
& $1931-1970$ & 1980 & 1981 \\
January & 5 & 0 & 0 \\
February & 7 & 0 & 0 \\
March & 35 & 3 & 32 \\
April & 77 & 35 & 39 \\
May & 113 & 189 & 108 \\
June & 112 & 161 & 159 \\
July & 145 & 109 & 156 \\
August & 130 & 119 & 160 \\
September & 125 & 71 & 82 \\
October & 114 & 151 & 54 \\
November & 30 & $?$ & $?$ \\
December & 6 & 0 & 0 \\
Total & 899 & $\geqq 838$ & $\geqq 790$ \\
\hline
\end{tabular}

Source: Ilaco (1981).

During the growing period in 1980 it was noticed that weeds did not constitute a serious problem on the wet areas, whereas these areas are usually severely infested with weeds when sorghum is the only crop.

The yields per plot for 1980 and 1981 are given in Table 3 and Table 4 respectively.

The analysis of variance of the 1980 experiment shows that the sorghum yield varies significantly $(P<0.01)$ with the rice cultivar with which it was combined, but that the rice cultivars had no significant influence on the rice yields nor on the total yield per plot. The yield of sorghum and rice varies significantly per replication $(P$ $<0.01$ ), but the combined plot yield is not influenced by the replication.

The analysis of variance of the 1981 experiment shows that the rice cultivar had no significant influence on the yield of sorghum, rice or the two combined. Here

Table 3. Plot yields ( $\mathrm{kg} / \mathrm{ha}$ ) of sorghum and rice in the sorghum-rice intercropping experiment, related to rice cultivar and replication, $1980 .{ }^{1}$

\begin{tabular}{lcccccc}
\hline Combination & \multicolumn{2}{l}{ Replication } & & & \\
\cline { 2 - 5 } & I & II & III & IV & V & VI \\
1. Sorghum & $170 \mathrm{w}$ & $340 \mathrm{~m}$ & $40 \mathrm{w}$ & $250 \mathrm{~m}$ & $360 \mathrm{~m}$ & $1060 \mathrm{~d}$ \\
IR 24 & 2560 & 1060 & 2910 & 1310 & 2250 & 1220 \\
2. Sorghum & $90 \mathrm{w}$ & $860 \mathrm{~m}$ & $130 \mathrm{w}$ & $970 \mathrm{~d}$ & $1190 \mathrm{~d}$ & $1490 \mathrm{~d}$ \\
IR 269-26-3-3-3 & 3050 & 1690 & 4010 & 1310 & 1820 & 1280 \\
3. Sorghum & $40 \mathrm{~m}$ & $430 \mathrm{~d}$ & $0 \mathrm{w}$ & $330 \mathrm{~m}$ & $0 \mathrm{w}$ & $860 \mathrm{~d}$ \\
Tau Ainho & 2720 & 1390 & 2190 & 2000 & 3360 & 820 \\
\hline
\end{tabular}

${ }^{1} \mathrm{~d}=$ dry, $\mathrm{m}=$ medium, $\mathrm{w}=$ wet. 
Table 4. Plot yields ( $\mathrm{kg} / \mathrm{ha})$ of sorghum and rice in the sorghum-rice intercropping experiment, related to rice cultivar and replication, $19811^{1}$

\begin{tabular}{lcccccc}
\hline Combination & \multicolumn{2}{l}{ Replication } & & & \\
\cline { 2 - 6 } & I & II & III & IV & V & VI \\
1. Sorghum & $700 \mathrm{w}$ & $1940 \mathrm{~m}$ & $2140 \mathrm{~d}$ & $180 \mathrm{w}$ & $380 \mathrm{w}$ & $2060 \mathrm{~d}$ \\
IR 26 & 2360 & 900 & 240 & 2240 & 2400 & 280 \\
2. Sorghum & $570 \mathrm{w}$ & $1750 \mathrm{~d}$ & $1930 \mathrm{~d}$ & $120 \mathrm{w}$ & $610 \mathrm{w}$ & $2770 \mathrm{~d}$ \\
IR 269-26-3-3-3 & 2210 & 590 & 590 & 2580 & 1610 & 390 \\
3. Sorghum & $120 \mathrm{w}$ & $2040 \mathrm{~d}$ & $1370 \mathrm{~m}$ & $30 \mathrm{w}$ & $1730 \mathrm{~d}$ & $2250 \mathrm{~d}$ \\
Tau Ainho & 3250 & 930 & 760 & 3790 & 1180 & 200 \\
\hline
\end{tabular}

${ }^{1} \mathrm{~d}=$ dry, $\mathrm{m}=$ medium, $\mathrm{w}=$ wet.

again the replication had a significant influence $(P<0.01)$ on the sorghum and the rice yields but not on the yields of the two crops combined.

Fig. 1 shows how the yields of rice, sorghum and the two crops combined vary with the soil moisture conditions. The averages of these yields are plotted against the soil moisture conditions for both years. Fig. 1 suggests that the yields of rice and

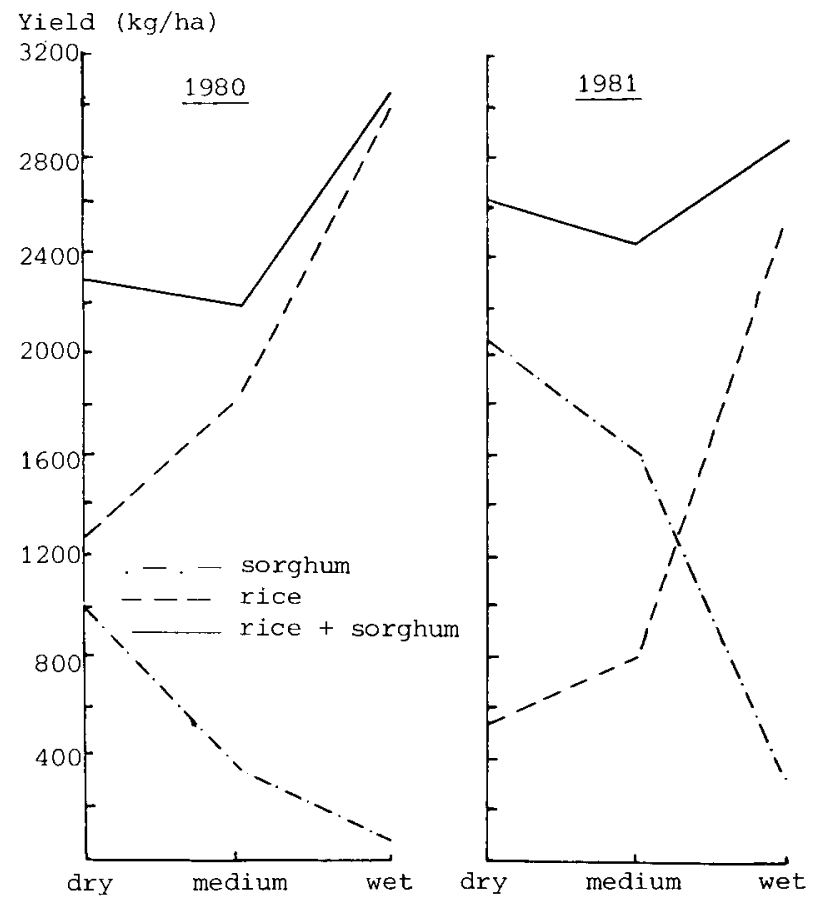

Fig. 1. The average yields of rice, sorghum, and rice plus sorghum under different soil moisture conditions in 1980 and 1981 . 
sorghum are seriously affected by the soil moisture conditions but that a combination of the two crops gives a fairly constant yield.

It is also noticed that the sorghum yields were higher and the rice yields lower in 1981 than in 1980 , although there was not much difference in the total rainfall during the growing season. The explanation for this difference should probably be sought in the detailed distribution of the rainfall during this period, but information on this is not available. Similarly, the fact that the rice cultivar influenced the sorghum yield in 1980 but not in 1981 may also be attributable to the distribution of rainfall.

\section{Conclusions}

Crop mixtures which include rice are found mainly in areas with high rainfall and well-drained soils (IRRI, 1974, p. 336-339; IRRI, 1978, p. 370-373; Steiner, 1982). Intercropping of rice and sorghum is not usual, as sorghum does not grow well in areas of high rainfall, while rice grows poorly in the drier areas suitable for sorghum. The results of these experiments show, however, that sorghum-rice intercropping may be useful under conditions of moderate rainfall combined with poorly drained soils. The main advantage is that rice grows well on areas which are subject to flooding, while sorghum yields better on drier areas. Areas which are sometimes flooded and sometimes dry produce intermediate yields for both crops. In this way it is possible to achieve a food production system which is less dependent on rainfall pattern. Other advantages are: (1) that rice suppresses growth of weeds on wet areas and (2) that by cultivating rice, optimum use is made of the high fertility of the low areas, which is brought about by the accumulation of fertile material from the higher areas.

\section{References}

Doggett, H., 1970. Sorghum. Longmans, London.

Ilaco, 1980. Agricultural research results, rainy season 1979. Pengko Pilot Project, Technical Note 12, Ilaco, Arnhem, Netherlands.

Ilaco, 1981. The soils of the Bor District. Pengko Pilot Project, Technical Note 25, Ilaco, Arnhem, Netherlands.

IRRI, 1974. Annual Report 1974. International Rice Research Institute, Los Baños, Philippines.

IRRI, 1975. Annual Report 1975. International Rice Research Institute, Los Baños, Philippines.

Steiner, K.G., 1982. Intercropping in tropical smallholder agriculture with special reference to West Africa. Schriftenreihe der GTZ 137. GTZ, Eschborn, Federal Republic of Germany.

Struif Bontkes, T., 1985. Sorghum-rice intercropping - a security system that saves Jonglei Nomads' cattle. Agriculture International, July/August 167-169. 